The Oxford Handbook of Strategy (2001), Chapter 30

\title{
Strategy, Heuristics, and Real Options
}

\author{
Bruce Kogut \\ Wharton School, University of Pennsylvania \\ (Phone: 215-898-1093, Fax: 215-898-0401, e-mail: kogut@ wharton.upenn.edu) \\ and
}

Nalin Kulatilaka

School of Management, 595 Commonwealth Avenue, Boston University

(Phone: 617-353-4603, Fax: 617-353-6667, e-mail: nalink@bu.edu)

We would like to thank Carliss Baldwin for many helpful comments, and managers of Lucent for a reality check on some ideas. 


\section{Looking Inward and Outward}

Strategizing is the application of heuristic frames to analyze the world and to generate normative evaluations of potential avenues of implementation. ${ }^{\mathrm{i}}$ Yet, like many professional schools caught between academics and application, strategy research is often ambivalent about the implications of valuing the development of heuristics. Because a test of a good heuristic is its application, the relevant community by which to evaluate such contributions appears often to be the commercial world.

This tension is probably more functional than commonly realized. Professional schools of business share, as Simon noted, commonalties with schools of design, e.g. engineering or architecture. Strategy research reflects competing ideas about how the world looks, or what the world needs. ${ }^{\text {ii }}$ However, like their counterparts in engineering or architecture, strategy researchers distinguish themselves from practitioners by their attention to an articulation of theory and evidence.

One of the most important bodies of strategic ideas at large today are associated with the notions of capabilities or core competence. The book by Gary Hamel and C.K. Prahalad Competing for the Future has sold more copies than any other Harvard Business School book. The resource based theory of the firm, which has seized the intellectual agenda from industry analysis, views the unique capabilities of the firm as the cornerstone of sustainable rents. 
Ned Bowman (1995) has made the distinction between strategies that look in the mirror and those that look through the looking glass. It is not surprising that during a time of restructuring and re-engineering, strategy researchers should shift the emphasis from industry analysis to the internal sources of competitive advantage. The international competition and the introduction of information technologies have, as the extensive literature on American competitiveness has documented, generated considerable competitive pressures on corporations.

This emphasis on looking in the mirror begs the question of how to choose among alternatives. Hamel and Prahalad (1994) essentially invert this framing by proposing the concept of white spaces in the topography of existing businesses to identify valuable avenues of exploration. This language is strongly reminiscent of the commonly made distinction between exploitation and exploration. ${ }^{\text {iii }}$

We propose that the real options literature provides an appropriate theoretical foundation for the heuristic frames suggested as ways to identify and value capabilities. Since capabilities are platforms that create a generic set of resources, they represent investments in future opportunities. The distinction between exploitation and exploration has an exact correspondence in the difference between net present value and option valuation. The attractiveness of real option thinking is only superficially in the obvious characteristic of forcing managers to think about the value of flexibility in response to uncertain events. The more fundamental contribution is to require that the valuation placed upon a strategy is derived from dynamic equilibrium prices in the market. In effect, real option valuation 
marries the resource based view with industry positioning by disciplining the analysis of the value of capabilities by a market test.

We proceed by first characterizing what are heuristics and how real option theory and core competencies are related through the concept of capabilities. Capabilities reflect irreversible investments, because of the costliness of transforming the organizational knowledge in a firm. We illustrate these ideas through a stylized mathematical description of the problem of adopting radical change. This formalization clarifies that the benefit of a real options heuristic is the imposition of a market test to derive the valuation of capabilities.

\section{Heuristics}

A good heuristic has four qualities: it is easy to use, easy to communicate, provides a better direction than ones currently employed, and motivates people who have to implement the strategy. The Boston Consulting Group growth matrix is the canonical heuristic. It requires only two data inputs of market growth and relative position. The famed ideograph of stars, dogs, question mark, and the cash cow have an Orwellian Rosebud value, i.e. they are comprehensible and memorable. ${ }^{\text {iv }}$ The implementation leads to a clear motivation. As the CEO of General Electric stated, the objective of GE's business units is to be number 1 or 2 in world markets. However, the not-so-minor drawback is that the heuristic often gives the wrong direction.

Because heuristics are intended to be used, they have many qualities that upset the norms of academic research. The objections come from all quarters. Sociologists point out that such 
heuristics reflect prevailing norms of style or conceptions of control. Cognitive psychologists note that heuristics are prone to type 1 and 2 errors, that is, managers ignore evidence of misfit and overstate the possibility of success. Social scientists are quick to criticize the absence of formal theory and empirical evidence. ${ }^{v}$ Ad hoc field research indicate that well-educated Ph.D. business faculty frequently moan over the humiliation of teaching heuristic frames that are not clearly derived from their formal education.

Heuristics are useful because formal theory often does not suggest operational rules, or is not credible, for the problems decisions makers confront in actual conditions. Since they are intended to guide action, heuristics are designed to motivate. From a normative perspective, overestimation is an evolutionary attractive property for assembling human effort; an emphasis on sober assessment screens out people who are most likely inclined to act. ${ }^{\mathrm{vi}}$ Because they are meant to influence action, they are biased toward current conceptions of the world; they are also liable to be dispensed as these conceptions change.

Heuristics have the advantage of countering some cognitive biases, but at a cost. In a study on plant scheduling, Bowman (1963) found that managers would do better if they used linear estimates from their experience rather than tried to optimize in response to each situation. In real time, the search for optimal strategies can be too costly or liable to be influenced by recency effects (e.g. the arrival of new information). Kunreuther (1969) modified these findings that rules cued to selective environmental information improve actual decision making. 
One of the merits of a heuristic is its real-time utility. Studies on innovation show remarkable tradeoffs between costs and time for innovations (Scherer, 1967; Mansfield, 1988). Field research and experimental evidence show ample evidence that people rely upon rules of thumb and known routines in situations constrained by time, even for simple problems for which there exist optimal rules. Because decisions must be made, managers and firms often transfer these sub-optimal rules to settings that are poorly suited to these proven heuristics. ${ }^{\text {vii }}$ The limits to the robustness of a heuristic are usually experiential, because the theory is rarely explicit or is ignored.

\section{Heuristics and Strategizing}

The history of strategic planning tools documents the applicability and limitations of heuristics. Following distinctions made in cognitive science, we separate a heuristic into its cognitive frame and the rules of search. A cognitive (or heuristic) frame refers to the 'representation' of the problem and solution space. The heuristic rules of search are the algorithms by which solutions are found in the represented solution space. ${ }^{\text {viii }}$

Table 1 compares three cognitive frames for developing business strategies. The BCG cash flow matrix "works" to the extent that the theory of scale and experience driving down cost is the proper characterization of value creation. From the initial data, it bootstraps from observations on market growth and relative positions to evaluate whether a firm can dominate a market. Though a fairly simple heuristic, it shared the common bias of its times that size drives success, as opposed to the more modest inference that size is the outcome of success. ${ }^{\text {ix }}$ 
Porter (1980) developed his industry analysis in the immediate aftermath of the oil shock and during a period of depressed corporate profitability. Its theory is derived from an industrial economics that appears as antiquated by contemporary advancements, but reflects the preoccupations of a time when the historical peaking of oligopolistic measures of concentration suggested that industry structure deeply influenced corporate performance. It is, in many ways, an inevitable implication of the BCG analysis that a world in which a few firms grow to dominance should lead to a focus on how to attain the conditions of structural stability. The initial data on industry forces serves to inform (though the mapping is not clear) the choice between low-cost and differentiation strategies. The implementation proceeds through an evaluation of the value-chain, with the criterion being contribution to profit. Compared to the requirements of the BCG growth matrix, the methodology is intensive in the use of data.

The core competence concept arose in the late 1980s during the height of re-engineering propelled by acquisitions and new information technologies. It is a direct response to the reputed financial pressures from financial markets dominated for the first time by institutional investors. ${ }^{\mathrm{x}}$ The formulation by Hamel and Prahalad (1994) suggests that the initial data are in the spirit of understanding the intended strategy of the firm that should be grounded in a distinctive competence. ${ }^{\mathrm{xi}}$ This competence is defined by three attributes: it should be 'extendable' to multiple markets, it should be hard to imitate, and it should satisfy a derived customer demand (Hamel and Prahalad, 1994: 202-207). 
The theoretical foundations to this view are several, from the reasoning on why knowledge is hard to imitate to the evolutionary theories of firm growth. From a decision theoretic perspective, the core competence framing lends itself readily to a real option interpretation. A real option is defined by an investment decision that is characterized by uncertainty, the provision of future managerial discretion to exercise timing, and irreversibility.

These three elements are jointly required for the application of a strategic options heuristic. An option has value only if there is uncertainty, though defining the relevant source of the uncertainty is not trivial. An operationally important element of design is the provision of discretion, such as the staging of an R\&D project to correspond to discrete points of go-no go decisions.

Irreversibility is an easily overlooked feature and signifies the inability to costlessly revisit an investment or decision. A classic example is the BCG categorization of the "dog" product division which a firm should divest, assuming there is a market. However, the ability to divest a poorly performing division is, as Winter (1987) observes, rarely exercised without incurring a loss on the original investment. In this context, irreversibility is the inability to recover the investment costs already expended for the product division.

\section{Capabilities as Strategic Options}

This definition of a core competence as a strategic option is close to the argument put forth by Barney (1986) regarding the resource-based view of the firm. To Barney, the creation of entrepreneurial rents is fortuitous. If managers understood the value creation process, the 
knowledge through imitation would lead to the immediate erosion of these rents. ${ }^{\text {xii }}$ The presence of a strategic factor market serves to arbitrage the value of these assets to guarantee a competitive return. (We return to this observation later to motivate the explicit use of a traded security for valuation of a real option.)

The important difference between this early statement of the resource-based view of the firm and core competence is the latter's insistence on the value of a resource as derived from its future but uncertain use. In the sense that Barney relies on market valuations to back into his identification of unique assets, he is consistent with the view that the market values the use of these assets in reference to their potential use by firms bidding for their ownership. But he makes an incomplete inference, namely, that these firms must have differential information. An equally plausible insight is that firms differ in their opportunity set, inclusive of the organizational features that are costly and time consuming to acquire. Consequently, some firms will discover profitable projects, where the 'excess rents' are earned on their organizational, not physical capital, assets.

Real option theory bridges the positioning and core competence by dynamically deriving the value of capabilities simultaneously from two discrete operating states: their value as "is" and as "could be."xiii The "as is" evaluation is a net present valuation based upon an evaluation of the range of possible payoffs to operations currently in place. The option value is derived from the discretion to alter these operations to take advantage of future opportunities. In this simultaneous valuation of both operating states (they are clearly dependent), the analysis 
derives the valuation by creating a shadow security based on the market value of the strategic factor.

It is the identification of the opportunity set, as established through market valuations, that should drive the identification and valuation of core competence. Some writers fail to make this observation altogether. For example, Teece, Pisano, and Shuen write:

We define those competences that define a firm's fundamental business as core. Core competences must accordingly be derived by looking across the range of a firm's (and its competitors) products and services... The degree to which a core competence is distinctive depends on how well endowed the firm is relative to its competitors, and how difficult it is for competitors to replicate its competences (1997: 516).

This statement is, however, rather problematic. It derives a core competence from the description of a firm's businesses, and in comparison to competitors. Finally, it notes that distinctiveness depends on a firm's endowment and the difficulty for the assets to be copied.

The missing element in this analysis is, of course, value. A firm may be well endowed with patents making it difficult for competitors to imitate. However, the important question is whether these endowments, which we might also call more generically the knowledge of the firm, is useful not only to current, but also to future applications. This question is not answered by a notion of dynamic capabilities, or of combinative capabilities, unless the 
normative criterion is the identification and investment in core competences in reference to their potential uses. This objection is not petty, for it is easy to imagine that without market discipline on the analysis, the potential candidates for core competence quickly multiply. ${ }^{\text {iv }}$

There is another way to think about this problem, suggested by Winter (1987), as a broader formulation along the lines of optimal control. Winter (1987: 180-181) states, "From evolutionary theory comes the idea that a state description may include organizational behavioral patterns or routines that are not amenable to rapid change, as well as...more conventionally defined assets. It is by this route that a variety of considerations that fall under the rubrics knowledge and competence may enter the strategic state description."xv This suggestion seems odd, for optimal control requires an excessive belief in the rationality and knowledge of decision-makers, a belief that Nelson and Winter (1982) have strongly criticized. However, it is not a bad heuristic frame (Winter uses this term) if some of the insights of a capabilities approach is properly specified. A conventional formulation is to describe the characteristics of the state description and allow the decision maker discretion over a few control variables, e.g. technologies or output. A transformed formulation deprives the decision maker of control over some variables and, in effect, captures the constraints and opportunities of capabilities through a richer description of the given state in a decision context.

Consider the example of flexibility through the installation of new automated equipment. A conventional approach assumes that this technology enters into the description of the state and provides the decision maker with the choice of whether to exercise flexibility. However, a 
new capability is not determined by the capital purchase but by the presence of an organizational system that identifies and supports such flexibility. Because technology can be bought, or peopled hired into a firm, it is the organizational constraints that are often the most binding. Robert Stempel, the former head of General Motors, noted:

We've tried automation without knowledgeable workers, and it doesn't work. We put a tremendous amount of automation and electronics into our Cadillac plant in Hamtranck. And we couldn't run it because our people didn't understand what we were asking them to do. ${ }^{\text {xvi }}$

The study by Ittner (1996) found that a major problem in the exercise of flexibility at General Motors was that the accounting system focused on unit labor cost variances; there was no measure for whether flexibility was under- or over-utilized.

This accounting problem is reflected also in the capital budgeting problem. Just like accounting variances do not measure flexibility properly, net present value techniques wrongly estimate the value of building capabilities. ${ }^{\text {xvii }}$ The important insight into the failure at General Motor is that new technology and organization are complements. Even though technology can be purchased, the organizational complement requires a longer period of experimentation and gestation. In other words, the organizational value of capabilities depends upon the potential uses of flexibility in future but uncertain states. 
It is, consequently, reasonable to think of a firm's technology and organization as forming a coherent and dynamic set of capabilities whose value is derived from their value in future and stochastic states of the world. Such capabilities as speed of production or the ability to produce a particular quality are created through the possession of a set of technologies and of organizing principles. Given these capabilities, the firm is endowed with the resources that may be exploited strategically in the market.

\section{New Capabilities as Organizational Discontinuities}

It is useful, before starting, to explain why investments in capabilities are irreversible because of the tight coupling of technology and organization. The close relationship between organizing principles and technology is apparent in standard definitions in the literature on innovations and organizational sociology. Scott (1995: 227) defines technology as including "not only the hardware used in performing work but also the skills and knowledge of workers, and even the characteristics of the objects on which work is performed." Scott's definition encompasses the standard economic distinction between new products and processes and the embodiment of human capital formation in better techniques and products.

By technology, then, we mean the physical and human capital stock; by organization, we mean the way physical capital and people are jointly coupled through organizational routines, processes, incentive schemes and governance structure. For example, a system of mass production consists of the serial placement of capital equipment coupled with an assembly line of workers performing standardized tasks and under staff supervision. The technology is embedded in the equipment; the organizational knowledge is the principle by which work is 
arranged and supervised in conjunction with the use of this technology.

An area of debate has been whether to treat major technological innovations as radical or incremental. The organizational literature, especially Tushman and Anderson (1986), has offered the resolution that these innovations can be characterized as radical or incremental depending upon whether they destroy or enhance a firm's competence. (See also Henderson, 1993.) This resolution raises the more fundamental problem that a firm, by its ability to recruit new engineers and managers, should have the capacity to alter its technological competence. The costs of switching to a technology should, by this reasoning, consist of the costs of hiring new individuals trained in the new science or engineering technology. Yet, clearly, the difficulty of adopting new capabilities cannot be explained by the relatively open recourse to the labor market in most advanced capitalist countries.

This reasoning ultimately leads to the consideration that the radicalness of an innovation has less to do with the novelty of the technology than its conformity with existing knowledge of the firm, i.e. the ways by which work is organized and power is distributed. Since the way work is organized will vary by firms, then the radicalness of a technological innovation can not be determined independent of a particular organizational context. Switching, or adoption, costs are strongly contingent on the current organization of work.

If radicalness of a technological innovation is a question of the organization, it follows that the potentially most radical kinds of innovation are those which alter directly the method by which work is organized. New ways of doing things are often difficult to understand and implement. 
They also pose, by their very nature, threats to the existing agreement on the allocation of power. ${ }^{\text {xiii }}$

To draw out why, consider the very important literature in organizational behavior concerning the suitability of particular organizational and technological combinations. One of the most perplexing questions in organizational behavior is the failure to identify clear matches between technologies and organizational structures. Yet, the findings are rather ambiguous in this regard. The line of work begun by Woodward and later the Aston school that linked performance to particular technological and organizational combinations has not resulted in clear relationships. Indeed, the most robust finding appears to be between organizational size and output volume rather than between particular structural and technological configurations. Indeed, even the findings between size and authority relations have been found to be sensitive to contextual variables, such as culture. ${ }^{\text {xix }}$

Dosi and Kogut (1993) proposed that the failure to find robust relationships has been due to the tendency to theorize element to element correspondence, such as high volume production with vertical hierarchy. ${ }^{\mathrm{xx}}$ (See figure1a.) The empirical results do not show that these are complements when other factors are controlled. Alternatively, the correspondence might be set to set, where a set of organizational practices maps onto a set of technologies. The data might not reveal that $\mathrm{A}$ and $\mathrm{B}$ exist as complements; all we observe is $\mathrm{A}$ and $\mathrm{C}$ and $\mathrm{D}$ and $\mathrm{B}$. Complementarities need not be unique between any given technology or organization, but they still should be relationally bounded. The recent findings by MacDuffie (1996) on "bundles" of human resource practices in auto plants indicate that there is a logic that relates organizing 
practices to each other, and to technologies. (See figure 1b.) As suggested in the opening citation of Robert Stempel, the experience of General Motors and other car manufacturers, as confirmed in MacDuffie's study, is that adopting the new capabilities of flexibility and speed requires changes in automation and organization. Between these two sets, there are many functionally equivalent complements, but there are no unique element-to -element correspondences. $^{\mathrm{xxi}}$

This description captures also the idea of co-evolution of technology and organization through two key features. First, technology and organization do not represent random assignments, nor is their coupling simply at the discretion of managers. Rather, the matches of a technology and organizing principle are constrained to reasonable set-to-set correspondence. However, within these 'developmental' constraints (to borrow from biology), improvements in technology and organization are correlated through experiential learning. For example, the introduction of mechanical equipment to move the incomplete chassis from one line to the next required the organizational innovation to increase the 'tightness' of the coupling of serial work processes in the factory. In other words, technology and organization are dynamically coupled in their evolution.

The tight coupling of technology and organization means that the costs of organizational change means that firms will persist in their old ways beyond the recommendation of the net present value. This persistence defines a range of inertia, or what we call a hysteresis band. Because organizational change is disruptive and hence discontinuous, managers hesitate to 
change radically their organizations, hoping perhaps that future states of the world would provide more appealing environments.

Figure 2 provides a simple illustration of this point. A firm can choose between two complementary systems, called low and high variety. The important issue is whether the relative value of gaining the capability of variety is enough to offset the costs of discontinuous change. The choice of capabilities is, as we depict it, derived from the market price placed on variety. Because of uncertainty over the evolution of the value of variety and the costs of adoption, managers rationally might choose to persist with inferior techniques before they are confident of future developments.

In the analysis below, we develop a modeling framework by which to examine this hysteresis band and the complementarity of organization and technology contingent upon a stochastic parameterization of the environment. The formal description explains how investments in organizational and technological capabilities are derived from their evaluation in the market. We suggest that knowledge accumulates in terms of two activities: competence in the use of particular technologies and in the organizational capability by which this technology is applied.

The problem facing the firm is to choose this set such that it tries to maximize its value in reference to its expectations on the evolution of prices and innovations in capabilities. In this formulation, the nature of the environment and strategy play an important role in shaping the 
capabilities of the firm. This problem is dynamically complex, as the firm must consider not only how its choice influences current profits, but also the learning of future capabilities.

This descriptive formulation clarifies two central claims. The current capability set and prevailing environment and market structure influence the choice and performance of a set of capabilities. The second claim is that there is a set to set correspondence between families of technology and organization that bound the feasible bundles of practices; but there is no unique element to element correspondence between a particular organizational practice and technology.

\section{A Formal Description}

The market price of a similar firm provides the most direct link between the performance of a capability set and prevailing market conditions. This market price is not the value of the core competence. Rather, it permits a valuation of the organizational capability by identifying a correlated asset in the relevant 'scarce factor' market. Value of a capability is then inferred (at times calculated) from the observed price dynamics that replicate the payoff to the real option. This replication is the device through which market discipline is imposed on the identification and selection of core capabilities, thus imposing financial market discipline.

To elucidate the intuition, consider again the framing of a real options problem. The organizational assets of a firm provide an option to spend a fixed amount to procure a new capability by purchasing a physical asset at the end of one year. If the option is exercised, then the resulting project value has the risk characteristics of an existing traded firm. For example, 
a pharmaceutical firm is considering an entry into biotechnology. It currently has a strong capability in conventional drug development that provides an option to enter into biotechnology at an estimated cost. This cost is idiosyncratic to this firm. However, once it enters into the market, its new business carries a market risk similar to other biotechnology firms. This example illustrates why the price of other firms does not give the value of the core capability, since the cost of entry is idiosyncratic to each firm. However, the price dynamics of other firms provide information on the factors (e.g. risk) that drive the value of the option to enter in this market.

The value of a financial option depends on the current share. Black, Merton, and Scholes derived this value through an option pricing formula. The simple, but critical innovation, was their eventual recognition that by composing a replicated portfolio, the value of the option could be perfectly tracked by a levered position in the traded stock. Therefore, a risk-free portfolio can be constructed by holding a combination of the stock and options. ${ }^{\text {xxii }}$ Hence, once the range of possible future stock prices is known (from its volatility), the market price of the option can be inferred by risklessly discounting the possible option payoffs.

In many instances, there may not be a traded security whose price perfectly tracks the value of the resulting capability. In such cases, we can use one of two possible tracks to retain the market discipline. First, there maybe a bundle of pure assets (an index) that captures risk characteristics of the capability. For example, "crack spread" on crude oil as a proxy for the gross operating margin of an oil refinery; the SOX/SXE equity index of semiconductor manufacturers serves as a proxy for the value of the production from a chip fabricating plant. 
Second, the value of the capability depends on the price of product or factor prices whose risk is spanned by traded assets in the economy. The value of the capability then is obtained by explicitly specifying the profit function using these prices as an argument.

A simple example is a microprocessor, whereby a quality-adjusted price can be expressed as the ratio of price to the processing speed (or "mips" for millions of instructions per second). An increase in processing speed implies that the price for one 'mips" has declined. This quality-adjusted price of the output enters the profit function. Thus, the price dynamics of chips directly drives the expected cash flow from operating the 'as is' assets and from possibly exercising the option to exploit the 'could be' investment.

\section{The economic environment and quality adjusted prices}

Let's use this last example to specify, descriptively, the method by which the price dyanamics of the scarce factor is inferred through observations on a traded output. We then will take this description of the price dynamics to derive the profit function. Once we have this profit function, we then can describe the qualitative properties of how an investment in new organizational capabilities influences the definition of a core competence. The fundamental conclusion of this exercise is to motivate the definition of a core competence as the capabilities that provide the best response to prevailing market opportunities.

In order to identify and value a core competence, we must specify the evolution of the qualityadjusted price which we call $\theta$. However, since $\theta$ is not a pure security but is the observed price of a scarce factor, its price characteristics need not necessarily evolve according to its equilibrium risk characteristics. Local supply and demand conditions and technological innovation determine the evolution of $\theta$. In particular, the expected rate of appreciation of $\theta$ 
may be different from its risk-adjusted equilibrium rate of return. Hence, the risk-neutral dynamics of $\theta$ will depend not only on the risk-free rate of interest but also on the difference between the equilibrium and actual growth rates of $\theta .^{\text {xxiii }}$

We assume $\theta$ to be exogenously determined and characterize its evolution by stochastic process

$$
\Delta \theta_{t}=\underbrace{\mu\left(\theta_{t}, t\right) \Delta t}_{\text {Deterministic Growth }}+\underbrace{\sigma\left(\theta_{t}, t\right) \Delta Z_{t}}_{\text {Smoothly evolving uncertainty }}+\underbrace{\kappa d q}_{\text {Discrete innovations }}
$$

where $\mu$ is the expected growth rate of $\theta, \sigma$ is its instantaneous volatility, $\Delta Z_{t}$ is standard Normal distributed, $\mathrm{d} q$ is a Poisson process with intensity parameter $\lambda$ and $\kappa$ is the random percentage jump amplitude conditional on the Poisson event occurring. ${ }^{\text {xiv }}$

This discrete-time process captures the main features of the notion of a scarce factor market with technological innovation. ${ }^{\mathrm{xxv}}$ The drift term reflects the expectations regarding technological progress. For example, the performance of memory semiconductors follows a fairly predictable path, with performance improvements occurring every few years and prices declining subsequently.

Changes in the quality-adjusted price may also reflect unpredictable shifts in consumer preferences. For example, an increase in oil prices would lead consumers to prefer cars which save in fuel consumption. As long as these changes are fairly smooth, it seems reasonable to capture this uncertainty in volatility. 
Other changes may be more radical, such as the arrival of new organizational innovations. These changes would appear as a sudden jump in price to a firm. Recall that these are qualityadjusted prices. The introduction of assembly-line methods at Ford appeared to competitors as a sudden decrease in price. However, as Raff and Bresnahan (forthcoming) show for the history of the automobile, part of the competitive effect of new techniques was accomplished through changes in quality, holding the nominal price the same. They estimate that qualityadjusted prices fell by 5\% a year from 1906 to 1940 ; about $60 \%$ of this decline was to due to falling production costs and $40 \%$ to improved quality. We capture these impacts of innovative change by allowing price to evolve in response to quality and process innovations.

A market-traded proxy for the quality-adjusted price of computer chips can be constructed as the price index of chip making firms. Such an index will span the relevant risk characteristics. The rate of return on the index will proxy the equilibrium return. However, to the extent that the growth rate of the quality adjusted price deviates from the traded index, we correct the actual price process. This deviation will enter into the risk neutral representation of the option pricing model as a short-fall from equilibrium akin to a convenience yield. ${ }^{\mathrm{xxvi}}$

Since the total risk characteristics of the quality adjusted price, $\theta$, is similar to that of the proxy variable, the volatility can be estimated from the market for the chip company stock index. In fact, options contracts on such an index (SOX/SXE) is traded at the Philadelphia Stock Exchange. The implied volatility of these options provides a market source for information on the standard deviation $(\sigma)$ given in the above equation. 


\section{Profit Functions}

Having described the evolution of quality-adjusted prices, we can now turn to describing the relationship between capability sets of the firm and its profit function. Consider a firm that has the set of capabilities $c$, where $c \in C$ is the set of all feasible capabilities. ${ }^{\text {xxvii }}$ The firm faces exogenously determined "quality adjusted prices", $\theta$. The single-period profit obtained when operating under the set of capabilities $c$ and facing prices $\theta_{t}$ is denoted $\Pi\left(\theta_{t}, c\right)$. This simple description captures the idea that firms are heterogeneous and their profits are determined both by the price of output and their organizational capabilities.

Given this set of capabilities and the realization of $\theta$, we examine how the firm chooses its investment and production strategy. As an example, consider the case where $C$ contains "mass" and "lean" production families with their associated organizational structures. Each family of production techniques can contain many distinct technologies. They are, however, coupled with the same organizational structure. Hence, a technology family refers to all technologies that can be operated within a single organization. ${ }^{\text {xxviii }}$

Suppose the firm is currently employing technology in the "mass" production family, i.e $\boldsymbol{c}_{\boldsymbol{m}}^{\boldsymbol{i}} \in$ $\boldsymbol{c}_{\boldsymbol{m}} \in \boldsymbol{C}$. The firm's problem is to decide what capabilities it should use in the current period. Specifically, its choices are (a) continue using $c_{m}^{i}$ (b) continue in the same family but make incremental technological improvements by employing a better mass production technique, $c_{m}^{i}$, or (c) make discontinuous organizational switch and employ lean production technique, $c_{l}^{k}$. Choices a and b reflect 'as is' evaluations; only c involves a 'could be' alternative. 
Furthermore, a capability provides a dynamic representation of the firm. A firm's capabilities not only serves to meet the current demands but also places it in a position to make further investments to launch new products to meet changing demand conditions. A capability endows the firm with an ability to change. A static profit function, therefore, can not be a complete description of a capability. The description of capability must capture the dynamics that determine the type, level, and timing of investment needed transform capabilities over time.

In other words, we must consider explicitly the costs of switching from one capability to another, be it from mass into lean, or conventional pharmaceutics to biotechnology, from a current capability such as mass production to a technique in the lean production family. Switching from one capability to another incurs large costs due to reorganization. ${ }^{\text {xix }}$ We denote these large organizational costs of switching as $\Delta_{i j}$. For example, the cost of switching from $\mathrm{c}_{\mathrm{n}}$ (mass production) to $\mathrm{c}_{1}$ (lean production) can be denoted as $\Delta_{m l}$.

Within an organizational capability, however, switching costs are small, but not insignificant. At the same time, continuing within the same family enables the firm to capitalize on local learning effects. If the firm continues in $c_{m}^{i}$ or moves to a better mass technique $c_{m}^{j}$ then it will subsequently learn by doing. However, switching from the $\mathrm{i}^{\text {th }}$ to the $\mathrm{j}^{\text {th }}$ technology may still incur technological costs. We define the local learning benefits in mass production as $\boldsymbol{o}_{\mathrm{mm}}$ and technological switching costs $\delta_{\mathrm{ii}}$ 
To summarize the magnitude of switching costs between all combinations of capabilities and technologies, we denote the cost of switching from $\boldsymbol{c}_{\boldsymbol{m}}^{i}$ capability to $c_{l}^{j}$ will be

$$
\delta_{m l}^{i j}=\underbrace{T_{i j}}_{\text {Technological change }}+\underbrace{\Omega_{m l}}_{\text {Organizational learning }}
$$

where

$$
T_{i j}=\left\{\begin{array}{cl}
\overbrace{\delta_{i j}}^{\text {technological cost }} & \text { if } i \neq j \\
\underbrace{-\delta_{i i}}_{\text {technological learning }} & \text { if } i=j
\end{array} \quad \Omega_{i j}=\left\{\begin{array}{cl}
\overbrace{o_{m l}}^{\text {organizational cost }} & \text { if } \mathrm{m} \neq l \\
\underbrace{-o_{m m}}_{\text {organizational learning }} & \text { if } \mathrm{m}=l
\end{array}\right.\right.
$$

Consider a special example where mass production family $\mathrm{c}_{\mathrm{m}}$ contains two technology modes $\boldsymbol{c}_{\boldsymbol{m}}^{1}$ and $\boldsymbol{c}_{\boldsymbol{m}}^{2}$ and lean production family $\boldsymbol{c}_{\boldsymbol{l}}$ contains a single technology mode $\boldsymbol{c}_{\boldsymbol{l}}^{3}$. Table 2 presents the switching matrix containing the technological and organizational cost pairs. A negative entry indicates learning value from continuing to use the same technology or organization. A larger sign reflects a larger value.

\section{Table 2}

More generally, the diagonal elements in the switching cost matrix will contain negative entries indicating the learning value. 
We can now write down the firm's maximization problem. Each set of capabilities $\boldsymbol{c}_{\boldsymbol{m}}^{\boldsymbol{i}}$ has an accompanying profit function that is obtained by solving the usual profit maximization problem:

$\Pi\left(\theta, c_{m}^{i}\right)=\max _{y \in c_{m}^{i}} \theta \cdot y$

where $\theta$ is a vector of quality adjusted input and output prices and $y$ is the vector of input and output levels that are determined by the capability set. This simple expression indicates that the firm's ability to choose the best strategy is contingent on its organizational resources.

\section{Critical Capability Set}

\subsection{Static Profit Maximization when there are no Switching Costs:}

To fix ideas, let us first consider the static case where the firm maximizes its single-period profits. Suppose the firm can costlessly obtain any feasible capability in $C$. Then we can define a static capability $\mathrm{c}^{*}$ as

$$
c^{*}(\theta)=\underset{c \subseteq C}{\operatorname{argmax}}[\Pi(\theta, c)]
$$

(Argmax simply picks the capability that achieves the optimal response for a given $\theta$.) In our simple example, $\mathrm{c}^{*}$ picks an element from either mass or lean families depending on the respective profit functions and the particular realization of $\theta$.

\subsection{Static Profit Maximization with Switching Costs}


Consider now the case where switching between capabilities involves costs, e.g. corporate or business reorganization. The critical capability set depends not only on $\theta$ and the characteristics of the various profit functions, but also on the currently employed capability set. For instance if the firm is currently using $c_{m}^{i}$, the optimal single-period profit maximizing capability set is given by the solution to the following problem:

$$
\Pi\left(\theta_{t}, c_{m}^{i}\right)=\max _{c_{l}^{j} \in C}\left[\Pi\left(\theta_{t}, c_{l}^{j}\right)-\delta_{m l}^{i j}\right]
$$

Figure 3 illustrates this choice in the special case where mass and lean families each contain only a single technique. In a costless world, the lean technique dominates globally the mass technique. However, with switching costs, the relevant comparison is between the profit function of the currently employed mass technique and the profits of the lean technique net of switching costs. When $\theta$ falls below the intersection point $\theta^{*}$, the static decision rule calls for switching families.

\subsection{Dynamic Value Maximization}

The static analysis ignores the impact of the current capability choice on future choices. When future values of $\theta$ evolve stochastically, the current decision influences all future decisions as well. The decision by a mass producer of cars to invest in flexible manufacturing using lean production runs the risk that the American market suddenly decides to buy large recreational vehicles made best by standard mass production techniques. But now they face the problem that they are invested in lean manufacturing, and cannot easily switch back. The tight coupling of organization and technology is essential to understanding why capabilities 
radically changes the understanding of strategy as not only market competition, but as the selection of competence.

The way to incorporate the implications of future switching is to write out explicitly the problem over time. To do this, we no longer work directly with profit functions, but instead with a value function. While technically this problem is often hard to solve, its formulation is both intuitive and insightful. At a point in time (t), this formulation treats the present value of all future benefits given optimal future behavior, as represented by the value function $V\left(\theta_{t}, c_{m}^{i}\right)$. The value function is the solution of the well-known Bellman equation:

$V\left(\theta_{\mathrm{t}}, c_{m}^{i}\right)=\max _{c_{l}^{j}}\left[\left(\Pi\left(\theta_{\mathrm{t}}, c_{l}^{j}\right)-\delta_{m l}^{i j}\right)+\rho E_{t}\left[V\left(\theta_{\mathrm{t}+1}, c_{l}^{j}\right)\right]\right]$

where $c_{m}^{i}$, is the current capability pair (consisting of technology $\mathrm{i}$ and organization $\mathrm{m}$ ) and $\mathrm{j}$ and 1 are chosen from the set of feasible technologies and organizations at time $t+1$.

The Bellman Equation indicates that in each period the producer contemplates switching into a new capability. If it chooses capability $c_{l}^{j}$, it realizes benefits of $\Pi\left(\theta_{t}, c_{l}^{j}\right)$, but pays switching costs of $\delta_{m l}^{i j}$, and then arrives at the following period with value function $V\left(\theta_{\mathrm{t}+1}, c_{m}^{j}\right)$. This value depends on the capability chosen, $c_{l}^{j}$, as well as on the value of the state variable next period, $\theta_{t+1}$. Because still $\theta_{t+1}$ unknown at time $\mathrm{t}$, we take expectations; we also discount at rate $\rho$. 
In each period, the producer chooses the capability $c_{l}^{j}$ that maximizes the value of the project. This can be interpreted as the dynamic capability. More formally, we define the dynamic capability as

$$
c^{* * *}=\underset{c_{l}^{j}}{\operatorname{argmax}}\left[\left(\Pi\left(\theta_{\mathrm{t}}, c_{l}^{j}\right)-\delta_{m l}^{i j}\right)+\rho E_{t}\left[V\left(\theta_{\mathrm{t}+1}, c_{l}^{j}\right)\right]\right]^{\mathrm{xxx}}
$$

In the absence of switching costs, the solution to this optimization problem is simple: choose in each period the capability $c_{l}^{j}$ that maximizes $\Pi\left(\theta_{t}, c_{l}^{j}\right)$ in that period. This is the static critical capability discussed earlier. However, the presence of switching costs makes a forward-looking analysis necessary. The probability distribution of future prices affects the current choice of technology and organization.

This definition of a dynamic capability defines our reinterpretation of a 'core competence'. Core competence is the capability set (i.e. combination of organization and technology elements) that permits the firm to choose the optimal response for a given price realization of the strategic factor.

\section{Hysteresis and Costly Switching:}

With the above concepts, we can now analyze more fully the hysteresis band first given in Figure 2. If a firm is unable to choose the optimal response, these conditions lead to a competency trap that is expressed by a hysteresis band. In figure 4, the profit functions for two capability sets and the resulting hysteresis band is graphed. Since the dynamic analysis 
takes into account the impact of a current switching decision on all future switching decisions the hysteresis band is wider than in a static analysis.

For the costless switching case, the switch occurs exactly at where the two functions cross. The presence of switching costs has two effects: static and hysteretic. The static costs results in the switch occurring at the value of $\theta$ where profits associated with the new mode justify the costs of adopting new organizational capabilities of lean production. $\theta$ would have to decline past this point of switching in order to justify the switching costs back to mass production.

The band between the switching costs is underestimated by looking only at static costs. Because of the possibility that $\theta$ may revert back to previous values (e.g. due to a sudden drop in oil prices favoring gas-guzzling cars), the firm persists in its current mode and waits to see how prices evolve in the future. At some point, however, $\theta$ takes on values that justify not only the one-time switching costs but also the probability-weighted costs attached to switching back. The range of inaction associated between switching in and out of a capability set is what is defined as the 'dynamic hysteresis band' depicted in figure $4 .{ }^{\mathrm{xxi}}$

\section{Competency Traps and Learning to Learn}

Due the benefits of learning by doing, the firm's capabilities improve dynamically. In effect, the profit function can be described as shifting outward over time. By staying in its current activities, the firm becomes increasingly more competent. Techniques of mass production are expressed in well-understood routines that couple technology and people through known organizing principles of work. 
The danger remains, of course, that $\theta$ will suddenly jump to a range or cross a critical threshold in which the firm's competence is no longer profitable. In a sense, its accumulated learning in the old techniques is a 'competency trap.' By improving in mass production, it is less attractive to change organizational capabilities. Hence a firm might rationally preserve its way of doing things, because it has become so good at doing the (now) wrong thing. Dougherty (1995) has labeled this “core incompetence." Exploitation of current knowledge drives learning by doing; the pitfall is that this learning increases the rigidity of the firm.

To speed its transition to new techniques, the firm may decide proactively to allocate funding to exploration by experimenting with new techniques. This diversion of resources slows down its accumulation of learning with the current technology. At the same time, it increases the value of the option to switch to new capabilities by lowering the costs of switching. To characterize this wider menu of choices, figure 5 depicts the decision of a firm that has accumulated a particular breadth of knowledge in the current production techniques, as well as in learning derived from experiments with new methods. (We can think of these experiments as 'joint ventures', such as the Nummi venture between General Motors and Toyota.)

The net effects of learning are ambiguous and depend upon the rate by which new knowledge is gained through learning by doing relative to experimentation. In figure 6 , this comparison is graphed by showing the upward change in profit functions over time due to these two learning effects. By construction, we show the gains to experimentation dominating learning by doing. 
We can expect that the attractiveness of experimentation increases with time for two reasons. First, the drift of prices leads to the expectation that over time, the old techniques should be scrapped. Secondly, it is reasonable to think of the gains to learning as marked by eventual declining returns. As the 'technological opportunities' of the current capabilities are exhausted, the attractiveness of exploring in the new set of techniques should increase.

We expect, therefore, that investments in learning should follow a cyclical pattern. Indeed, the historical record suggests that the early experiments in mass production gradually dwindled. It would be consistent with this view to expect that the investments in incremental learning so often attributed to Japanese firms should also decline over time, as these opportunities are exhausted. It is not necessary to stipulate that for cultural reasons, Japanese firms are better learners than American firms are. Rather, a particular cross-section of time, Toyota had more to learn about how to expand its capabilities than Ford, which had after 60 years explored most of the terrain of how to organize mass production of standardized products. When there are few gains to exploration, allocation to exploitation of current capabilities dominate investments in incremental learning.

\section{Combinative Capabilities:}

Our portrayal of exploitative learning by doing as a process of discovering better matches between organizational and technological elements suggests a dynamic by which knowledge accumulates through recombination. This characterization of learning implies that the capabilities of firms can improve by a modular design. In this case, there is a higher order 
strategy rested upon the combinative capabilities of a firm to dynamically re-adjust its knowledge (Kogut and Zander, 1992).

We can make this similarity more transparent by analyzing in more detail the dynamic by which learning accumulates through recombination. This point is implicit in the argument of Baldwin and Clark $(1993 ; 2000)$ that the benefits of modularity are realized through exercising the embedded options to ratchet up improvement. They note that modularity allows for a better process of "mix and match" through an improved understanding of subsystems.

An intuitive way to understand their model is to compare two kinds of strategies of throwing dice. ${ }^{x x i i}$ Let the score on each die indicate performance. The first strategy is to toss both dice, and then to accept or reject the total. The second is to toss each separately, and apply the same decision rule to each die separately. The first strategy reflects an integrated design; the second, a modular design. The modular design allows for the possibility that one die scores a 5 , while the other only a 2 . In this case, the designer may decide only to toss the second die. By this process of mix and match, improves in design evolve through recombination.

These benefits are derived through the strong assumption that performance is the sum of independent draws, i.e. the outcome of tossing a die. There are two important implications from dropping independence of the draws. The first is that the benefits falls, because the experiments are correlated. Behaviorally, correlation in experiments captures realistically the limitations of any firm in designing independent projects; statistical correlation reflects the bias of managers in the projects they are willing to support. 
The second implication is that interdependence makes the design problem more difficult. For by fixing one of the die, the performance contribution of the second module is dependent not simply on its own efficiency, but also on its interaction with the first module. As a consequence, the optimization of a given set of modules does not guarantee that this evolutionary process can ever arrive at a "best" system. However, the notion of correlation also expresses tightly the idea that irreversibility is derived from the rigidity of competence in managing a particular set of interdependent organizational and technological elements.

This insight of correlated performance underscores why exploratory search is required. Implicit in any modular design is a system constraint. If the overall system performance is inferior to competing systems (e.g. lean production), then evolutionary learning through recombination within a given capability set leads to a competency trap. It is this evolutionary characterization of the learning process that provides the behavioral basis to the concept setto-set correspondence as defining a capability set.

\section{How Good a Heuristic?}

Strategic option theory is obviously a complex heuristic to apply. However, much like the BCG growth matrix does not need to measure costs, a core competence heuristic does not (always) need to value the option. Instead, through identifying the value of the competence as derived from market price of correlated assets, strategic option theory disciplines the core competence analysis to understand valuation as sensitive to competitive forces. These forces 
tend to limit the potential exploitation of a competence through a consideration of the effects on price and competition.

There are, however, several important complications to a strategic option heuristic. These complications provide important insight into the use of strategic options, and they also suggest the sub-optimal transfer of the heuristic to inappropriate settings. For illustration, we consider three problem areas.

\subsection{Competitive Interactions:}

The valuation of a strategic option requires an identification of a market price by which to derive the replicate the underlying asset. In financial markets, this price is easily given by stock or future prices. An important, and reasonable asssumption, is that exercising the option does not influence the value of the replicating portfolio.

This assumption does not hold always for strategic options for two reasons. First, by exercising an option to enter a market, a firm often influences prices through increasing supply. Second, by entering (or exiting) a market, competitors will alter their behavior. As a result, the market price is endogenous to the decision whether to exercise the option.

This problem is partly resolved by recognizing that the value of theta reflects the assessment

on entry. ${ }^{\text {xxiii }}$ But this assumption hardly provides insight into the identity of possible entrants and their strategic behavior. A structural approach is explicit regarding the nature of future competition. Kulatilaka and Perotti (1998) follow this approach by evaluating the decision to 
launch a new technology in the context of different conjectures about market structure. This solution marries the industry structure analysis to core competence, but through the stipulation that the analysis is forward-looking rather than focused on current market structure.

\subsection{Why Not Switch Now?}

The hysteresis band, we have suggested above, is influenced by the extent to which a firm has locked into a tightly-coupled system. Another explanation seeks to explore a question -often under-theorized in strategy research- concerning who gains from a decision to switch. Baldwin (1982) showed, for example, that owners would maintain inefficient plants in a bargaining setting to threaten workers from seeking higher wages. Kulatilaka and Marks (1988) analyzed why owners might choose to persist in an older, non-flexible technology as a way to signal a credible commitment to workers over wages. Both of the above papers suggest that bargaining strategies increase the value of maintaining older technologies and hence widen the hysteresis band.

A related issue is the difference between innovators and imitators. In the case of innovation, the profit windfall means that the bargaining problem is dividing a larger pie; Ford could win acceptance by increasing wages to $\$ 5$ a day. (See Raff, 1988.) For imitators, adoption is in the midst of declining revenues; there is less to redistribute and hence bargaining is more of a zero-sum game for some parties. The situation facing imitators is more of an endgame, where bankruptcy is a credible outcome. In this context, switching to new practices is more an issue of survival than improving fitness relative to rivals. These concerns form the central debate in 
the strategic thinking in Europe and elsewhere on whether firms should insist on flexible labor markets as a policy to respond to international competition.

\subsection{Stock Options as Compensation:}

This notion of flexibility in employment is often also extended to flexibility in compensation. There is a frequent belief that a large firm could be more flexible to seize opportunities if employees' compensation was contingent on outcomes. There are, however, two major problems to such an argument. Putting in option-like compensation clauses results in high variance of compensation for managers in comparable positions. As almost all studies on compensation show, pay and performance are not closely linked because it is demoralizing; employees do not believe that differentials reflect ability and they find the social comparison to be unfair. The implications for promoting what should be the source of gain to a firm namely, sustained coordinated and cooperative behavior- are invidious.

Second, compensation by options does not encourage flexibility. As Lambert et al. (1991) found, managers treat options that are in the money as wealth, and they consequently do not want to take decisions that eradicate their value. Unless a compensation scheme can be designed so that every decision is linked to a contingent payment, compensation by options is a disincentive for flexibility. Excessive incorporation of options in compensation is a heuristic, while appealing in its financial language in an age of institutional investors, whose application is detrimental.

\section{Conclusions}


Real option analysis provides the theoretical foundations to heuristics derived core competence. It offers the improvement by conditioning an understanding of competence in relation to a market test (e.g. Barney's notion of a strategic factor market) and by putting the organizational dilemma in central stage as the leading explanation for the irreversibility of investments in capabilities. In a narrow sense, it denigrates discounted cash flow analysis as the principal tool of understanding the value of a firm. But more profoundly, the recognition that the coupling of people and technology is a source of considerable option value challenges simplistic notions of firms as "pure asset plays".

It is reasonable to also ask whether the formal theory itself is liable to be implemented through a more usable heuristic framing. Reducing the mathematical formulation to linear approximations, e.g. the proposal by Bowman and Moskowitz (2002), makes this framing more plausible to the manager. However, the larger challenge remains whether the rigor of using an assessment of market valuation of options leads to heuristic frames that improve the quality of strategizing.

Through the link to the value of the embedded knowledge in organizational assets, the treatment of capabilities as strategic options deflects, ironically, a purely financial evaluation of the firm. Because organizations consist of coupled systems, the value of the firm is not reflected in the present value of its constituent parts, but in the combinative potential (i.e. the option value) of deploying these capabilities for innovation in existing markets or for addressing new markets. 
The implications of modularity as maintaining the option to recombine capabilities has an intuitive appeal to current trends in flat and flexibile organizations. ${ }^{\text {xxiv }}$ It suggests that firms are dynamic systems consisting of the complex coupling of technology and people through organizational design. The ironic conclusion to the sustained application of financial modeling to firms is that in the end, the fundamental basis of the value of the firm is its organizational capability to exploit current and explore future opportunities. 


\section{References}

Allison, Graham T., 1971, Essence of Decision: Explaining the Cuban Missile Crisis, Boston: Little, Brown.

Amram, Martha and Nalin Kulatilaka, 1999, Real Options: Managing Strategic Investments in an Uncertain World, Boston: Harvard Business School Press.

Baldwin, C. Y., 1982, "Optimal Sequential Investment when Capital is Not Readily Reversible,” Journal of Finance, 37: 763-782

Baldwin, C.Y. and K. Clark, 1992, "Capabilities and Capital Investment: New Perspectives on Capital Budgeting," Journal of Applied Corporate Finance, 5: 67-82.

Baldwin, C.Y. and K. Clark, 1994, "Capital Budgeting Systems and Capabilities Investments in U.S. Companies after World War II,” Business History Review, 68(1): 73-109.

Baldwin, C.Y. and K. Clark, 1993, "Modularity and Real Options," Boston: Harvard Business School, Working Paper, \#93-026.

Baldwin, C. Y. and K. Clark, 2000, Design Rules: The Power of Modularity, Cambridge, MA: MIT Press.

Barley, Stephen, 1990, "The Alignment of Technology and Structure through Roles and Networks," Administrative Science Quarterly, 35: 61-103.

Barney, Jay, 1986, "Strategic Factor Markets: Expectations, Luck, and Business Strategy," Management Science, 32 (10): 1231-1241.

Bartlett, Frederic, 1958, Thinking, New York: Basic Books.

Bowman, Edward, 1963, "Consistency and Optimality in Managerial Decision Making," Management Science, 9: 310-321.

Bowman, Edward, 1995, "Strategy History: Through Different Mirrors," Advances in Strategic Management, 11: 25-45.

Bowman, Edward and Gary Moskowitz, 2002, "The Use of Options Analysis in Strategic Decision Making," Organization Science, forthcoming.

Chandler, Alfred, 1962, Strategy and Structure, Cambridge: MIT Press.

Cohen, Michael and Paul Bacdayan, 1994, "Organizational Routines are Stored as Procedural Memory: Evidence from Laboratory Study,” Organization Science, 5: 554-568. 
Dixit, Avinash and Robert Pindyck, 1994, Investment Under Uncertainty, Princeton: Princeton University Press.

Dosi, Giovanni and Bruce Kogut, 1993, "National Specificities and the Context of Change: The Co-evolution of Organization and Technology," in B. Kogut, Ed., Country Competitiveness: Technology and the Organizing of Work, pp 249-262, New York: Oxford University Press.

Dougherty, Deborah, 1995, "Managing Your Core Incompetencies for Innovation," Entrepreneurship, Theory, and Practice, 19: 113-135.

Hamel, Gary and Prahalad, C.K., 1994, Competing for the Future: Breakthrough Strategies, Boston: Harvard Business School Press.

Hedlund, Gunnar and Dag Rolander, 1990, “Action in Heterarchies. New Approaches to Managing the MNC," in C.A. Bartlett, Y. Doz and G. Hedlund, Eds., Managing the Global Firm, New York: Routledge.

Henderson, Rebecca, 1993, "Underinvestment and Incompetence as Responses to Radical Innovation: Evidence from the Photolithographic Alignment Equipment Industry," Rand Journal, 24: 248-270.

Hull, John C., 1997, Options, Futures, and Other Derivatives, (3rd Edition), Upper Saddle River, NJ: Prentice Hall.

Ittner, Chris, 1996, "Exploratory Evidence on the Behavior of Quality Costs," Operations Research, 44(1): 114-130.

Ittner, Chris and Bruce Kogut, 1995, "How Control Systems Can Support Organizational Flexibility," in Edward Bowman and Bruce Kogut, Eds., Redesigning the Firm, pp 155182, New York: Oxford University Press.

Kahneman, Daniel and Dan Lovallo, 1993, "Timid Choices and Bold Forecasts: A Cognitive Perspective on Risk Taking," Management Science, 39: 17-31.

Kim, Dong-Jae and Bruce Kogut, 1996, "Technological Platforms and Diversification,” Organization Science, 7: 283-301.

Kogut, Bruce and Udo Zander, 1992, "Knowledge of the Firm, Combinative Capabilities, and the Replication of Technology," Organization Science, 3: 383-97.

Kogut, Bruce and Nalin Kulatilaka, 1992, “What is a Critical Capability?”, Reginald H.Jones Working Paper, Wharton School. 
Kogut, Bruce and Nalin Kulatilaka, 1994a, "Options Thinking and Platform Investments: Investing in Opportunity," California Management Review, 36(2):52-71.

Kogut, Bruce and Nalin Kulatilaka, 1994b, "Operating Flexibility, Global Manufacturing, and the Option Value of Multinationality," Management Science, 40: 123-139.

Kogut, Bruce and Nalin Kulatilaka, 2002, "Capabilities as Real Options," Organization Science, forthcoming.

Krugman, Paul and M. Miller, Eds., 1992, Exchange Rate Targets and Currency Bands, Cambridge: Cambridge University Press.

Kulatilaka, Nalin and Alan Marcus, 1992, "Project Valuation Under Uncertainty: When does DCF Fail?," Journal of Applied Corporate Finance, 5(1): 92-100.

Kulatilaka, Nalin and Stephen Marks, 1988, "The Strategic Value of Flexibility: Reducing the Ability to Compromise," American Economic Review, 78: 574580.

Kulatilaka, Nalin and Enrico Perotti, 1998, "Strategic Growth Options," Management Science, 44(8): 1021-1031.

Kunreuther, Howard, 1969, "Extensions of Bowman's Theory on Managerial DecisionMaking," Management Science, 16: 415-439.

Lambert, Richard, David Larcker, and Robert Verrecchia, 1991, "Portfolio Considerations in Valuing Executive Compensation," Journal of AccountingResearch, 29: 129-49.

Leach, J. Chris, 1994, "Good and Bad Variance in Valuing Production and Technological Expenditure Programs or Are Real Options Really Options?," mimeo, Wharton School.

Lincoln, James, 1993, “Comparison of Japanese and US Organizational Structures,” in B. Kogut, Ed., Country Competitiveness: Technology and the Organizing of Work, pp 54-74, New York: Oxford University Press.

MacDuffie, John Paul, 1996, "Human Resource Bundles and Manufacturing Performance: Flexible Production Systems in the World Auto Industry," Industrial and Labor Relations Review, 48(2): 197-221.

McDonald, Robert, and Daniel Siegel, 1984, "Option Pricing When the Underlying Asset Earns a Below-Equilibrium Rate of Return: A Note,' Journal of Finance (March) 261265.

Mansfield, Edward, 1988, "Speed and Cost of Industrial Innovation in Japan and United States," Management Science, 34: 1157-1168. 
March, James, 1991, "Exploration and Exploitation in Organizational Learning," Organization Science, 2: 71-87.

Merton, Robert C., 1976, “Option Pricing When Underlying Stock Returns are Discontinuous," Journal of Financial Economics, 3:, Jan./March, 125:144.

Milgrom, Paul and John Roberts, 1990, “The Economics of Modern Manufacturing: Technology, Strategy, and Organization, American Economic Review, 80: 511-528.

Minsky, Marvin, 1985, The Society of Mind, New York: Simon and Schuster.

Mintzberg, Henry, 1990, "Strategy Formulation: Schools of Thought," in J. Frederickson, Ed., Perspectives on Strategic Management, pp 105-236, New York: Harper Business.

Nelson, Richard R. and Sidney G. Winter, 1982, An Evolutionary Theory of Economic Change, Cambridge, MA: Harvard University Press.

Pindyck, Robert S., 1991, "Irreversibility, Uncertainty, and Investment," Journal of Economic Literature, 29(3): 1110-1152.

Piore, Michael and Charles Sabel, 1984, The Second Industrial Divide, New York: Basic Books.

Porter, Michael, 1980, Competitive Strategy: Techniques for Analyzing Industries and Competitors, New York : Free Press.

Raff, Daniel, 1988, "Wage Determination Theory and the Five-dollar Day at Ford," Journal of Economic History, 48: 387-399.

Raff, Daniel and T.F. Bresnahan, forthcoming, "Plant Shutdown Behavior during the Great Depression and the Structure of the American Motor Vehicle Industry," Journal of Economic History, forthcoming.

Scherer, F.M., 1967, "Research and Development Resource Allocation under Rivalry," Quarterly Journal of Economics, 81: 359-94.

Scott, W. Richard, 1995, Institutions and Organizations, Thousand Oaks, CA: Sage.

Selznick, Philip, 1957, Leadership in administration, a sociological Interpretation, Evanston, Ill.: Row, Peterson.

Servan-Schreiber, Jean-Jacques, 1969, The American Challenge, New York: Athenaeum.

Simon, Herbert, 1992, The Sciences of the Artificial, Cambridge: MIT Press, seventh printing. 
Szulanski, Gabriel, 1995, "Unpacking Stickiness: An Empirical Investigation of the Barriers to Transfer Best Practice Inside the Firm," Academy of Management Best Paper Proceedings, pp 437-441.

Teece, David, Gary Pisano, and Amy Shuen, 1997, "Dynamic Capabilities and Strategic Management," Strategic Management Journal, 18: 509-534.

Tushman, Michael and Philip Anderson, 1986, "Technological Discontinuities and Organizational Environments" Administrative Science Quarterly, 31: 439-465.

Useem, Michael, 1996, Investor Capitalism. How Money Managers are Changing the Face of Corporate America, New York: Basic Books.

Winter, Sidney, 1987, "Knowledge and Competence as Strategic Assets," in D. Teece, ed., The Competitive Challenge -- Strategies for Industrial Innovation and Renewal, Cambridge, MA: Ballinger, pp. 159-184.

Zander, Udo and Bruce Kogut, 1995, Knowledge and the Speed of the Transfer and Imitation of Organizational Capabilities: An Empirical Test," Organization Science, 6(1): 76-92. 
Figure 1

Correspondence of Technology and Organization

A. Element to Element:

Organizational

Technological

Vertical Hierarchy

High Volume

Production

A

B

B. Set to Set:

Organizational

Set of Different

Ways to Achieve

Flexibility
Technological

Set of Different

Automated

Equipment Systems

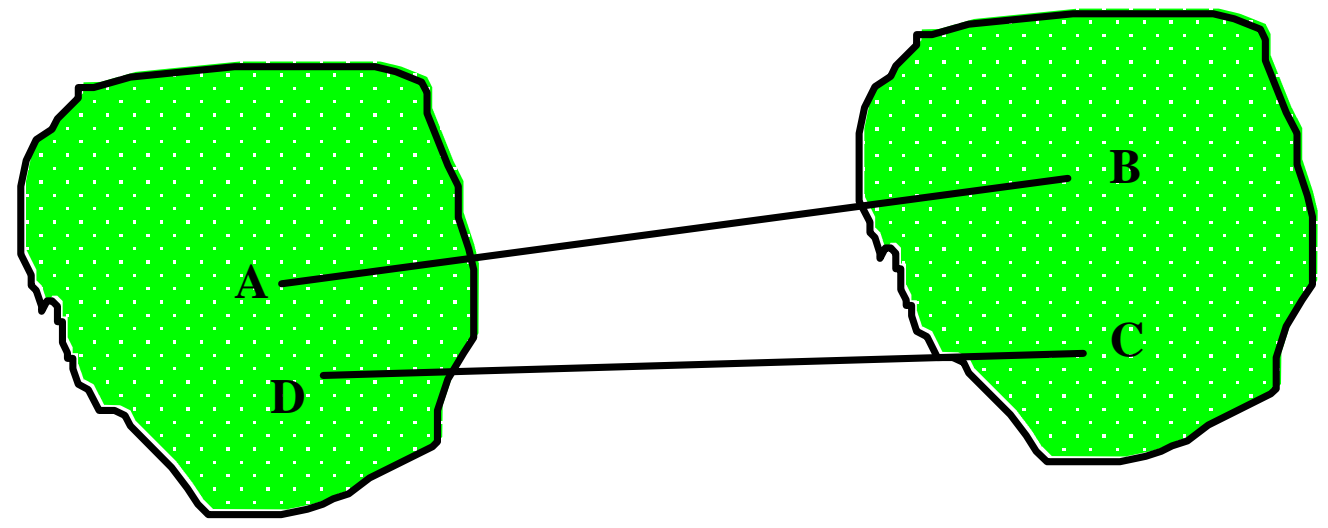




\section{Figure 2}

\section{The Implications of Hysteresis on the Choice of New Techniques}

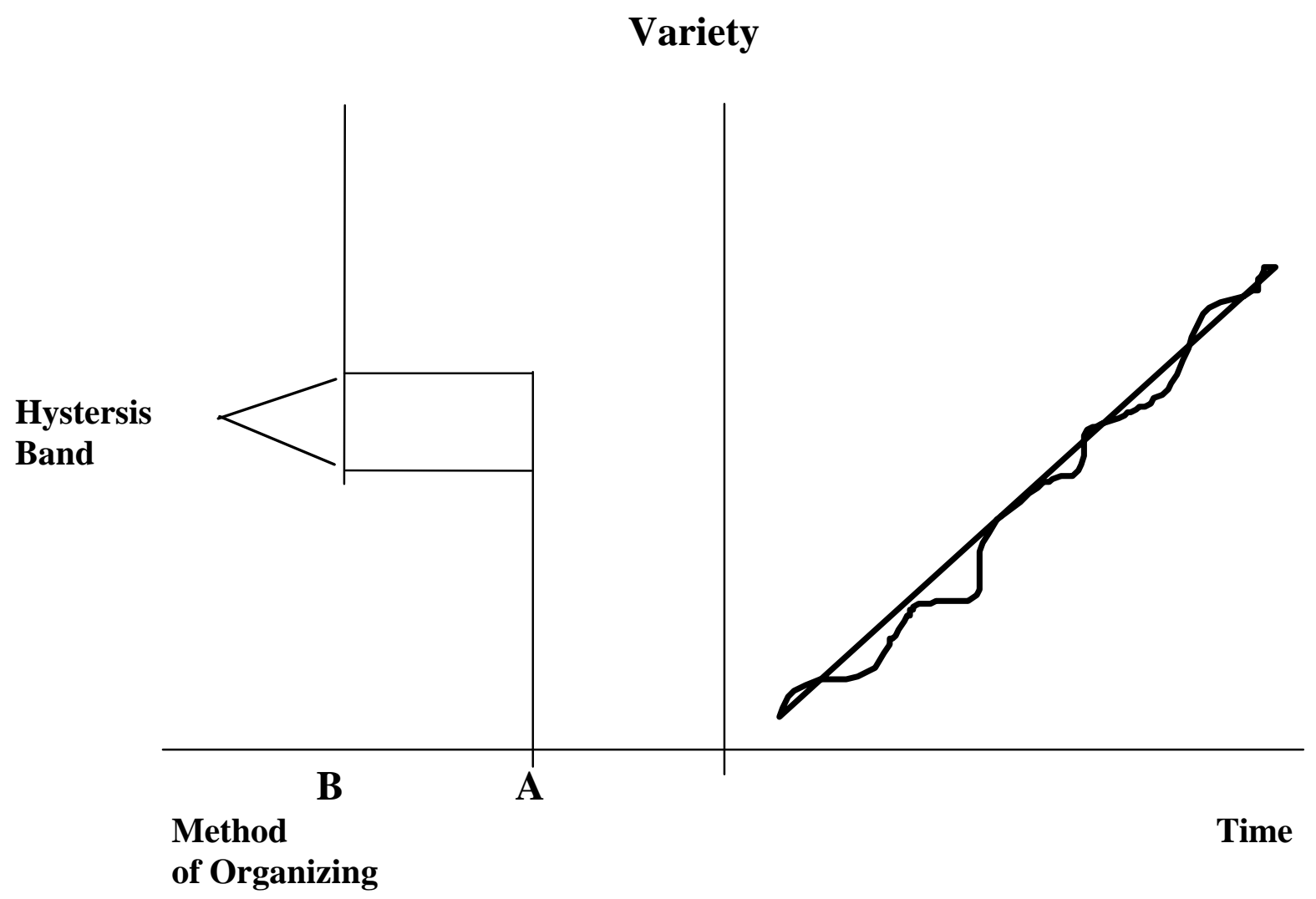

A: Mass Production

B: Toyotaism 


\section{Figure 3}

\section{Choice of Capability Set "Static Case"}

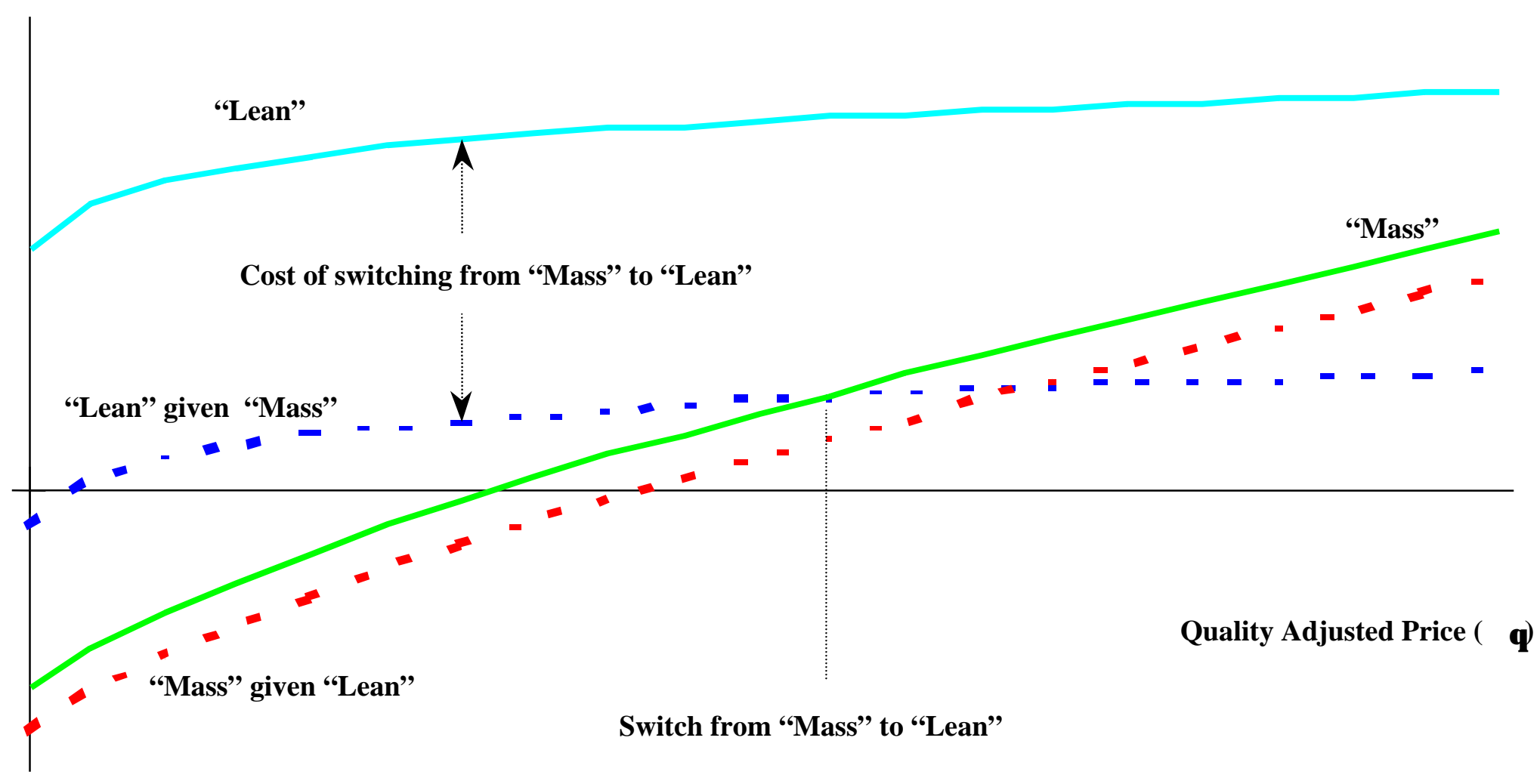




\section{Figure 4}

Static and Dynamic Hysteresis

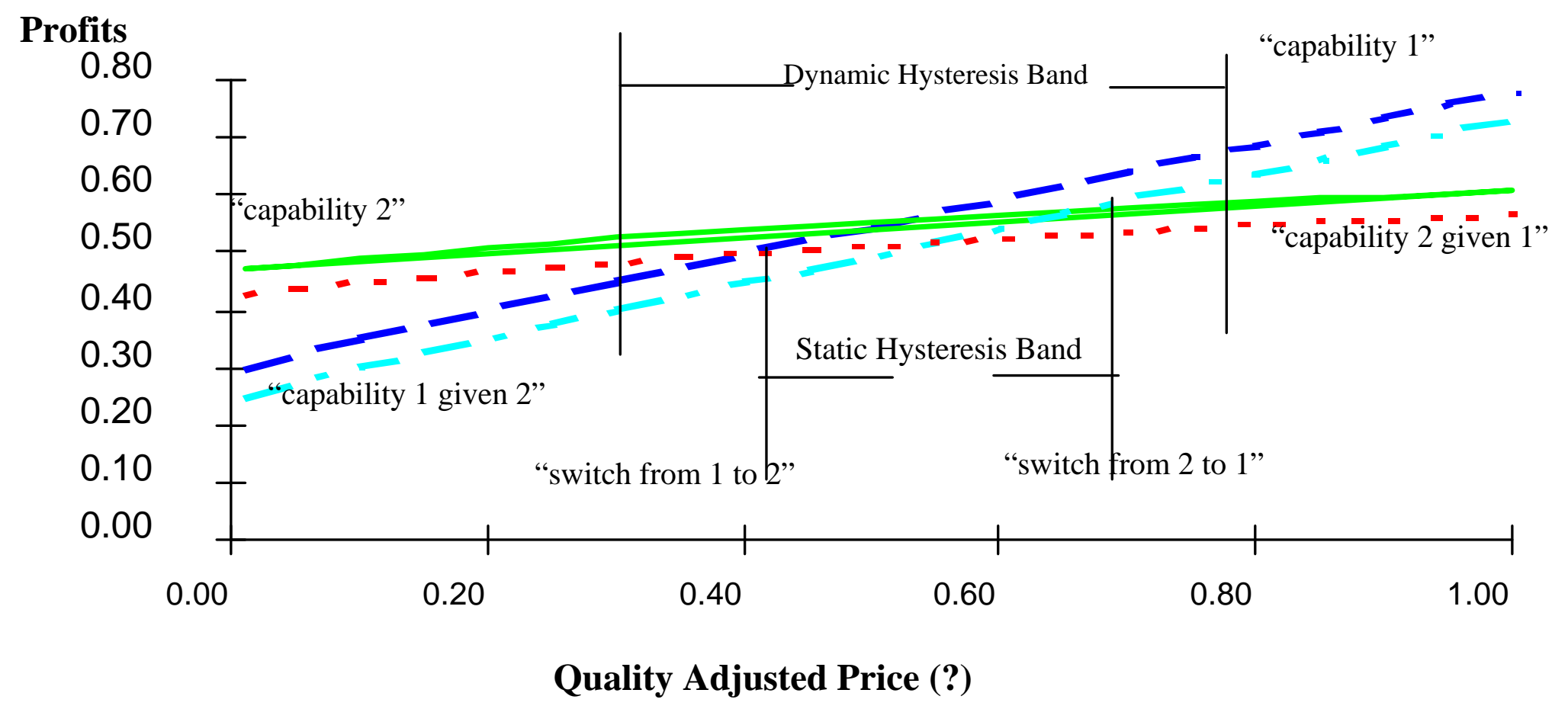




\section{Figure 5}

Expanded Capability Sets

\begin{tabular}{|c|c|c|c|}
\hline \multirow[b]{2}{*}{ Time $\mathbf{t}$} & Family i & Family $\mathbf{i}+1$ & Family $i+2$ \\
\hline & $\begin{array}{l}\text { Production } \\
\text { knowledge }\end{array}$ & $\begin{array}{l}\text { Experimental } \\
\text { learning }\end{array}$ & \\
\hline \multirow{4}{*}{ Time $\mathbf{t}+\mathbf{1}$} & & ily i & \\
\hline & $\begin{array}{l}\text { Production } \\
\text { knowledge }\end{array}$ & $\begin{array}{l}\text { Experimental } \\
\text { learning }\end{array}$ & \\
\hline & & \multicolumn{2}{|r|}{ Switch to Family i+1 } \\
\hline & & $\begin{array}{l}\text { Production } \\
\text { knowledge }\end{array}$ & $\begin{array}{l}\text { Experimental } \\
\text { learning }\end{array}$ \\
\hline
\end{tabular}


Figure 6

\section{Effects of Learning}

\section{Profits}

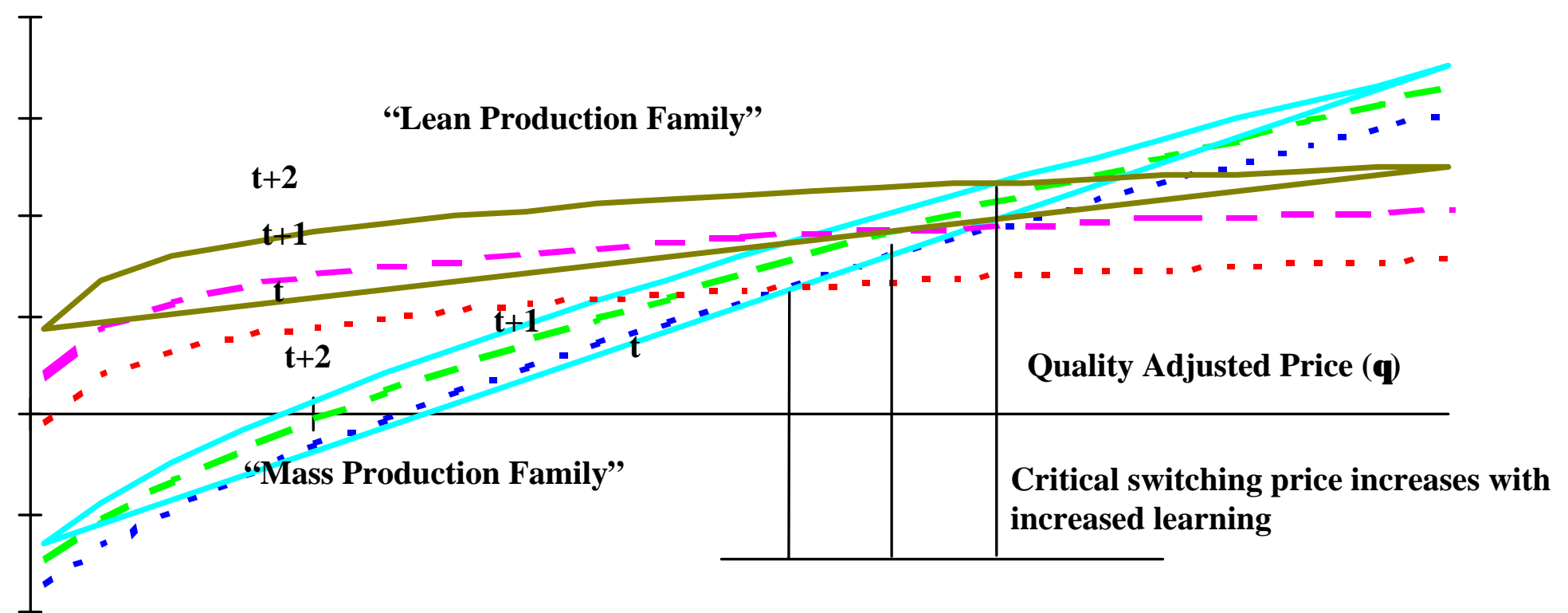




\section{Table 1}

\section{Strategizing as Cognitive Frames}

\begin{tabular}{|c|c|c|c|c|}
\hline Cognitive Frame & Theory & Initial Data & $\underline{\text { Analysis }}$ & Implementation \\
\hline $\begin{array}{l}\text { Experience } \\
\text { Curve (BCG) }\end{array}$ & $\begin{array}{l}\text { Scale and experience } \\
\text { drivers }\end{array}$ & $\begin{array}{l}\text { Attractive (growing) } \\
\text { markets }\end{array}$ & $\begin{array}{l}\text { Relative market } \\
\text { position }\end{array}$ & $\begin{array}{l}\text { Dominance by } \\
\text { scale }\end{array}$ \\
\hline Industry Analysis & Industrial economics & Industry forces & $\begin{array}{l}\text { Cost or Differentiation } \\
\text { Strategies }\end{array}$ & $\begin{array}{l}\text { Value-Chain } \\
\text { exploitation }\end{array}$ \\
\hline Capability & (Real Options) & Intended strategy & Core Competence & $\begin{array}{l}\text { Exploratory } \\
\text { business strategies }\end{array}$ \\
\hline
\end{tabular}


Table 2

$T_{i j}$ and $\Omega_{l m}$ Switching Cost Pairs

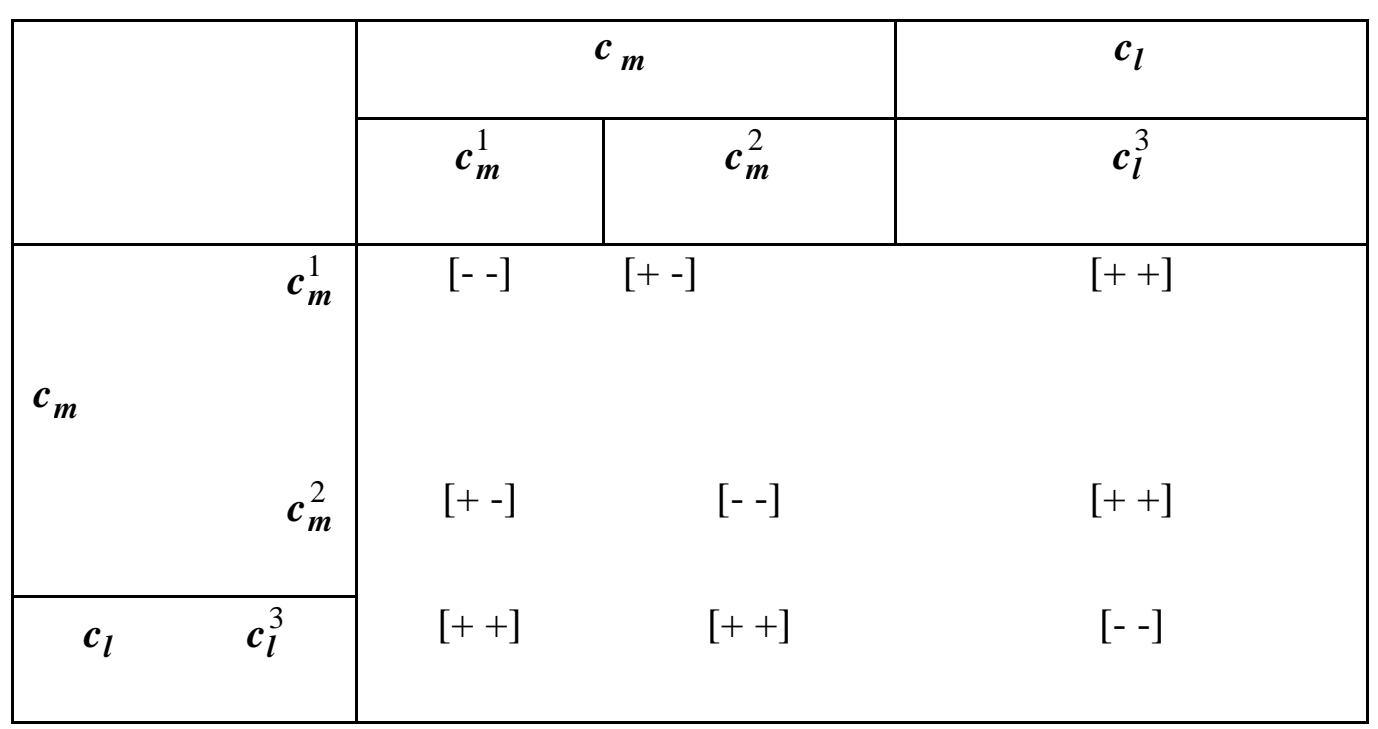




\section{Endnotes}

i This chapter is based on Kogut and Kulatilaka (1992; revision 1994); the published version Kogut and Kulatilaka (2002) considers in more depth organizational theories.

${ }^{\text {ii }}$ Mintzberg (1990) suggests there are no less than 10 schools of strategic planning.

iii See Hedlund and Rolander (1990) and March (1991).

iv This aspect of communicability has been underestimated. However, in an increasingly more integrated "community of practitioners," the importance of ideographic and metaphoric communication is critical to the success of information technology implementation and performance.

${ }^{\mathrm{v}}$ For overestimation bias, see (Kahneman and Lovallo, 1993); for a discussion of a lack of theory, see Simon's (1992) discussion of the professional school.

${ }^{v i}$ A interesting set of statistics are MBA entrance data. Whereas Wharton MBA's score at the top of the GMAT percentiles, their GPAs are usually around B+. These are smart people who do not like to study too much.

${ }^{\text {vii }}$ See Allison (1971) on frames; psychology experiments of Bartlett (1958) and Cohen and Bacdayan (1994) for evidence on schemata and sub-optimal transfer.

viii See Minsky (1985:74, 243-253) for an example. The definition of heuristic search is discussed in Bowman and Moskowitz (2002).

${ }^{\text {ix }}$ For examples of this bias, see Chandler (1962) and Servan-Schreiber (1969). Only in light of this backdrop is it possible to understand the contribution of Piore's and Sabel's (1984) counter-revolution in thinking about size and performance.

${ }^{\mathrm{x}}$ See Useem (1996).

${ }^{x i}$ Selznick (1957) was one of the first to develop the idea of distinctive competence, which was absorbed into the language of the early business policy literature, as well as of writings on the value-added chain.

xii The inimitable observations in Barney are more fully explicated in a related literature on knowledge of the firm. See Zander and Kogut (1995) and Szulanski (1995) for empirical studies that measure inimitable, or tacitness.

xiii See Dixit and Pindyck (1994) and Amram and Kulatilaka (1999) for extensive discussions on the application of real options. 
${ }^{\text {xiv }}$ One of the authors visited an optical fiber business unit of a large company. In response to a question about core competence, the factory and business managers identified the capability to quickly code the fibre in color packaging.

${ }^{\mathrm{xv}}$ Winter continues to recommend present value evaluation as adequate. However, when uncertainty is added, present value has to be adjusted, as shown later, to account for expectations.

${ }^{x v i}$ Fortune, 1992; cited by Bernard Wolf and Steven Globerman, "Strategic Alliances in the Automotive Industry," mimeo, York University, 1992. See also the discussion in Ittner and Kogut (1995).

${ }^{x v i i}$ Winter (1987) suggests net present value as a measure, which is appropriate for the case without uncertainty. Most surveys on the use of capital budgeting techniques show that almost all large corporate firms use net present value calculations for investment decisions. See Kogut and Kulatilaka (1992) and Baldwin and Clark (1992, 1994) for a discussion why investment in capabilities is not a net present value of cash flows but a real option valuation.

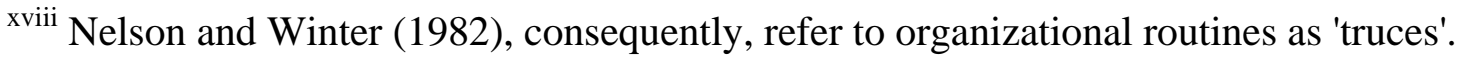

${ }^{\text {xix }}$ See the review given in Dosi and Kogut (1993) and the summary of the work comparing U.S. and Japanese organizations (Lincoln, 1993).

${ }^{x x}$ This point is implicit in the lattice formulation of Milgrom and Roberts (1990), where a firm's choice is constrained by technical complementarities. It is, however, difficult to see the implications from their formulation for the many studies on organizational performance.

${ }^{x x i}$ A good example of the linking of capability and technology is modular design, in which modularity provides an option to improve a product by component; however, the product design has to be backed by an organizational structure to allow specialization. See Baldwin and Clark, 1993.

${ }^{x x i i}$ As the stock price fluctuates, the portfolio weights to reflect the changing sensitivity of the value of the option to the stock price.

xxiii This is analagous to a dividend on a stock or convenience value derived from a commodity. See Chapter 13, Hull [1997] for a general model on valuing derivative securities. More extensive treatments can be found in Dixit and Pindyck (1994) and Amram and Kulatilaka (1999).

${ }^{\text {xxiv }}$ More generally, we could define this process in vector form over a set of Wiener 
processes. See Merton [1976].

${ }^{\mathrm{xxv}}$ For reasons of exposition, we work in discrete time.

${ }^{x x v i}$ See McDonald and Siegel (1984); an application of adjusting for the shortfall can be found in Kogut and Kulatilaka (1994b).

${ }^{x x v i i} \boldsymbol{C}$ will include technological and organizational characteristics as well learning opportunities.

${ }^{\text {xxviii }}$ For now we assume that families do not overlap, in that, each technology can only belong to a single family. This assumption can be easily relaxed.

${ }^{\text {xxix }}$ For simplicity we are assuming that switching across organizations only incur organizational costs. In effect, we assume that switching from any mass technology to any lean technology incurs the same cost. This can easily be generalized to include both technological and organizational costs.

${ }^{\mathrm{xxx}}$ For present purposes we ignore issues of risk. See Pindyck [1991] and Kulatilaka and Marcus [1991] for a treatment of the systematic risk in $\theta$.

${ }^{\mathrm{xxxi}}$ For an analysis of hysteresis effects of foreign direct investment under fluctuating exchange rates, see Kogut and Kulatilaka (1994a).

xxxii This exposition is due to Per-Goeran Persson's remarkable student paper written for a course on organizational design at the Stockholm School of Economics. His Monte Carlo simulation of the following description is available on request.

xxxii This endogeneity is similar to the work done on currency rate dynamics when traders form expectations on central bank policy. See the essays in Krugman and Miller (1992).

${ }^{\text {xxxiv }}$ Baldwin and Clark (1993) provide an interesting discussion and model of the value of modularity as options under the assumption of independence among the modules or development projects. An issue that cannot be pursued here is the observation that the value of the firm rests in managing the dependence among these modules; otherwise, a policy of outsourcing, e.g. a Toyota production system, can equally manage independent modules for eventual downstream assembly. 